\title{
Phenomenology as a Dynamic Process
}

\author{
Shulamit Reinharz \\ Brandeis University
}

Thomas Luckmann's article, "Reflections on Common Sense, Science and the Specialization of Knowledge," is a formidable paper on which to comment. The problem with which it deals is difficult, and the methods it uses do not fall neatly into a single discipline. I would categorize it more as philosophy than sociology of knowledge although Luckmann himself referred to it as a piece of work in the sociology of knowledge. I categorize it as philosophy because, to my mind, it does not construct concepts from observations of actual, identified societies or from language-in-use. Rather, the argument seems more deductive to me, in the sense that it begins with categories rather than having those categories emerge from examined experience. In fact, because it proceeds without reference to lived reality of specific individuals, it seems very removed from the basic principles of phenomenology, a method which attempts to create knowledge in a somewhat different way.

I understand Luckmann's paper as a taxonomy, i.e., a set of definitions which are placed in relation to one another. His taxonomy builds a system of categories of types of knowledge and refines our understanding of these categories. It yields a refined but ungrounded classification of types of knowledge. Taxonomies, or ways of cataloguing the contents of something, highlight the diversity of the parts, the connections among the parts, and the relationships of the parts to the whole. They can be a useful heuristic device.

But how is a taxonomy refutable? How can $I$ argue against a taxonomy? I could discover another element that is not part of the taxonomy and I could ask how one would deal with this piece. I could ask for it to be stretched or redesigned in some way. I could suggest a taxonomy that is more parsimonious, more aesthetically appealing, or has greater explanatory power. I could also judge a taxonomy to see if it is useful for a particular problem at hand. Or I could say (and this is the direction of the comments I would like to make) that a taxonomy is really only complete if the relationship between the parts is explained in a dynamic way. Luckman's taxonomy seems static or homeostatic; it seems rooted in a structural-functionalist model of society in which things exist because "society needs them." This taxonomy lacks conflict, and yet we know that conflict inheres in everyday life and science, as well as between them.

Perhaps the most marvelous taxonomy of all is Darwin's taxonomy of flora and fauna in which the parts were brought together by the principle of evolution. This principle not only explained the relationship among the parts but also helped us understand new phenomena as we encountered them. The attractiveness of the principle of evolution within the taxonomy of flora and fauna lies also in the fact that it explains the transformation of one part into another part. Luckmann could make his taxonomy more helpful if he would describe the transformation of the parts and the processes that hold the parts 
together. For instance, what is the transformational process by which common sense is converted into science, or science is then converted back into common sense? What is the process by which experience is sedimented into subjective stocks of knowledge, to use Luckmann's language? What is the process by which subjective knowledge is objectified into social knowledge? How do we get from one place to the other?

I think these questions are particularly germane to us as researchers and teachers. First, it is always the process of transformation with which we are concerned. Hopefully, we help transform students through the processes of teaching and mentoring. We are always changing things and being changed by creating conflict. In our research we help transform experience and observation into products which are consensually validated as knowledge. Our products are our books, papers, and talks. Our analyses are consensually validated by peers, audiences, and bosses in this socially stratified society. If we do not get this consensual validation, it becomes increasingly difficult to produce. Of course, there are always some great ones among us who can proceed without this validation.

Although many ways exist of transforming experience into knowledge (e.g., artistic, experimental, human scientific), we are concerned with one special way. The way with which we are concerned is phenomenological. Phenomenological methods are constrained by their reliance on people who are alive and verbal. We cannot deal phenomenologically with phylogenetic and ontogenetic problems. We can deal only with individuals who use language.

All methods are concerned with the transformation of experience into products which are consensually validated. But not all methods pay attention to all of these transformations. The phenomenological transformation has five steps. People interested in the human science approach claim that other social science methods do not adequately consider how these five steps or five transformations affect the validity of their claims to knowledge. People who identify with a phenomenological methodological orientation are more likely to attend to these transformations in their own work. Here are the five steps as I see them:

1. A person's experience is transformed into actions and language that become available to him/her by virtue of a special interaction $\mathrm{s} / \mathrm{he}$ has with another person(s). In this case the other is a phenomenological researcher who creates a situation or context in which the person's inchoate lived experience becomes available to him/her in language. That's the first transformation.

2. The researcher transforms what $s /$ he sees or hears into an understanding of the original experience. Because we can never experience another person's experience, we rely on data the subject produces about that experience, and we produce from that our own understanding. That's the second transformation.

3. The researcher transforms this understanding into clarifying conceptual categories which he or she believes are the essence of the 
original experience. Without doing that, one is simply recording, and recording is not enough to produce understanding.

4. The researcher transforms those conceptual categories that exist in his/her mind into some sort of a written document (or other product such as a picture, poem) which captures what s/he has thought about the experience that the other person has talked about or expressed in some way. That's another transformation. In all these transformations, something can be lost and something can be gained.

5 . The audience of the researcher transforms this written document into an understanding which can function to clarify all the preceding steps and which can also clarify new experiences that the audience has. This is where the inductive principle leads.

We would like, in phenomenological research, to have all of these transformations be self-conscious processes. We are frequently dissatisfied with survey research, for example, since there is not often an effort there to make the person's experience available to the audience.

Another way of thinking about these transformations is to see this chain as a series of steps in which the private becomes more and more public. The chain begins with the private world of the individual; this becomes public to the researcher; then the researcher makes it public to colleagues; from there it reaches wider audiences. In this regard, it is interesting to think about those situations under which you can create some sort of interaction in which the private becomes public for some purpose. Feminists have thought about this issue a lot. Until the Women's Movement took hold again in the 1960's, women walked around with a lot of private knowledge which had no public status. Then, through groups (e.g., consciousness-raising groups, task forces) in which women were the exclusive members - not tokens or minorities-their experience became validated by others. Then this validated experience sometimes became transformed into written documents which were later transformed into public documents which helped other women clarify their experiences.

I mention this phenomenon for two reasons. First, it seems that the construction of groups with homogeneous gender had a lot to do with the clarification of individuals' experience. This is something to think about when we do our research. What is the proper context needed in order to understand an individual's experiences? You might not always be the appropriate phenomenological researcher for a given person's experience because of your manner of speaking, your gender, your age, or whatever. When I did research on elderly people two years ago, I was always selfconscious about this issue of context. Am I the right person to enable elderly people to express their experiences? We learn from the example of the Women's Movement that certain situations are more felicitous than others for the expression of one's experiences. Second, if we ever wonder whether or not phenomenological research, or linking the private and the public, matters in the long run, I think that by looking at the transformation of society via the Women's Movement we can see how much it does matter. We can see how great the impact can be if we can create documents for the public which help clarify their experiences. This can lead us all to have insights about new actions that we want to take. 